\title{
GEOGRAFIA E PODER LOCAL: \\ hoteleiros, poder público municipal e entidades representativas em Campo Mourão/PR
}

geography and local: relations among hotels, public power and municipal entity representative in Campo Mourão/PR

\author{
Larissa de Mattos Alves ${ }^{1}$ \\ Márcia da Silva ${ }^{2}$ \\ aa $\boldsymbol{A a a}_{a}$
}

\begin{abstract}
Resumo
A rede social do turismo em Campo Mourão - PR é formada por atores locais, principalmente: prestadores de serviços hoteleiros, poder público municipal e entidades representativas. Este trabalho, que tem por objetivo a analise de tal rede social, inicia-se com esclarecimentos teórico-conceituais a respeito das relações de poder, articulação de interesses, formação de grupos de poder. Finalizando os apontamentos teóricos, apresentam-se as redes sociais enquanto um aporte conceitual para análise das relações de poder. A segunda parte deste trabalho está pautada em entrevistas sobre o poder local e as relações sociais estabelecidas entre os atores do setor turístico. As entrevistas foram realizadas com prestadores de serviços turísticos, membros do poder público municipal e entidades representativas do turismo local. A amostra selecionada totaliza 32 entrevistados vinculados ao turismo local. Feitas observações sobre os atores e grupos mais relevantes, este trabalho finaliza com a identificação e análise da rede social do turismo local.
\end{abstract}

Palavras-chave: Relações de Poder; Grupos de Poder; Turismo; Redes Sociais.

\begin{abstract}
This work aims to identify and analyze the power relations that make up/ form the social network of tourism in Campo Mourão - PR. While local actors have been selected providers of hotel services, the municipal government and the representative entities in Campo Mourão. Organized into three chapters, this work brings in his first chapter theoretical and conceptual clarification, regarding the relations of power, its forms and scales in which they settle. It is also theoretically addressed the articulation of interests and the formation of groups of power with emphasis on economic power, and the relationships of these groups with the State. Concluding the theoretical approaches, there are social networks as a contribution to conceptual analysis to the relations of power. The second part of this work is grounded in interviews on local and social relations between the actors in the tourism sector. The interviews were conducted with tourist service providers, members of the municipal government and representative entities of tourism in Campo Mourão. The selected sample totals 32 respondents linked to local tourism. Made observations on the most relevant groups and actors, this paper concludes with the identification and analysis of the social network of local tourism.
\end{abstract}

Key words: Power Relations. Power Groups. Tourism. Social Networks.

\begin{abstract}
Resumen
La red social de turismo en Campo Mourao - PR és formada por los actores locales, en especial: los proveedores de servicios de hotel, el poder municipal y los órganos representativos. Esta obra, que tiene como objetivo el análisis de dicha red social, se inicia con la clarificación teórica y conceptual acerca de las relaciones de poder, articulación de intereses y formación de grupos de poder. Acabado los enfoques teóricos, las redes sociales se presentan como un insumo conceptual para el análisis de las conexiones de poder. La segunda parte de este trabajo se guía por entrevistas sobre el gobierno local y las relaciones sociales entre los actores del sector turístico. Se realizaron entrevistas con prestadores de servicios turísticos, los miembros del gobierno municipal y los órganos representativos del turismo local. La muestra seleccionada asciende a 32 encuestados vinculados al turismo local. Se hicieron observaciones sobre los actores y grupos relevantes. Así, este trabajo concluye con la identificación y el análisis de la red social de turismo local.
\end{abstract}

Palabras-clave: Conexiones de poder; Grupos de poder, Turismo, Redes sociales, Campo Mourão.

(1) Mestre em Geografia (UEM), Professora na Universidade Estadual do Paraná - Campus Campo Mourão - Av. Comendador Norberto Marcondes, 733, CEP: 87303-100, Campo Mourao (PR), Brasil. Tel: (+55 44) 35181880 - larissamattosalves@hotmail.com

(2) Prof ${ }^{a} \mathrm{Dr}^{\mathrm{a}}$ da Universidade Estadual do Centro-Oeste, R. Simeão Camargo Varela de Sá, 03, CEP: 85040080 - Guarapuava (PR), Brasil. Tel: (+55 42) 36298100 - smarcias@superig.com.br 


\section{INTRODUÇÃO}

Este trabalho tem por objetivo identificar a rede social do turismo em Campo Mourão - PR e a análise das relações de poder que influenciam o setor localmente.

É fácil atrelar o Turismo unicamente às viagens por lazer, porém as viagens a negócio e trabalho não podem ser desconsideradas pelo setor. Esse público tem a mesma importância para o turismo, pois é considerado ainda um viajante que gera menos efeitos negativos no contato com residentes e que deixa mais recursos nos destinos do que os viajantes a lazer. Vêm dos turistas de negócios “(...) o maior gasto médio per capita registrado desde 2004, início da série histórica, segundo revela o Estudo da Demanda do Turismo Internacional no Brasil divulgado pelo Ministério do Turismo" (BRASIL, 2012).

O turismo de Campo Mourão agrega fluxos constantes, brandos e rotineiros causados pelas atividades produtivas e pelos serviços regionais, com raras grandes concentrações de visitantes por lazer, o que somente acontece durante grandes eventos. Mais do que identificar a rede social do turismo em Campo Mourão e a análise das relações de poder que a influenciam, espera-se, com este trabalho, contribuir com apontamentos e indicar padrões de relacionamentos de Campo Mourão que possam ser observáveis em outras localidades.

Assim, o presente trabalho está organizado em três momentos. O primeiro tem por objetivo trazer alguns esclarecimentos teórico-conceituais. Elaborado com fundamentos bibliográficos, apresenta e discute as relações de poder, suas formas e as escalas em que se estabelecem, bem como a articulação de interesses e a formação de grupos de poder, com ênfase aos grupos de poder econômico e suas relações com o Estado, o poder político e grupos de interesses. Finalizando os apontamentos teóricos, há uma apresentação sobre as redes sociais enquanto um aporte conceitual e metodológico para a análise das relações de poder.

A segunda parte deste trabalho resulta da realização de entrevistas semi-estruturadas. O roteiro para as mesmas foi elaborado com perguntas abertas sobre o poder local e as relações sociais estabelecidas entre os atores do setor turístico. As entrevistas foram realizadas com prestadores de serviços turísticos, membros do poder público municipal e entidades representativas do turismo em Campo Mourão. A hotelaria, os membros do poder público e as entidades representativas são considerados grupos de poder do turismo local. Seus membros quando considerados individualmente, ou mesmo enquanto grupo, serão considerados atores do turismo local.

Seguindo as orientações das bibliografias utilizadas nesta pesquisa, opta-se pela apresentação dos atores do turismo local segundo os grupos aos quais pertencem: poder público, poder econômico (prestadores de serviços hoteleiros) e entidades representativas. Tal organização se justifica por facilitar a compreensão das próximas análises ao seguir um padrão já estabelecido pelas orientações teóricas. Os prestadores de serviços hoteleiros foram representados por todos os dezesseis hotéis e pousadas do município. Quanto ao poder público municipal, foram realizadas entrevistas com dez dos membros da estrutura de governo da Prefeitura Municipal. Foram selecionados os representantes de secretarias e fundações mais próximas da gestão do turismo. Dentre as entidades representativas do setor turístico, foram priorizados os órgãos de gestão e de articulação atuantes no turismo municipal.

A amostra selecionada totaliza 32 entrevistados vinculados ao turismo local, no entanto estes representam um ou mais papéis, pois ao fazer parte de uma rede, o ator é reconhecido pela pluralidade de papéis que desempenha, o que vai direcioná-lo a um número maior de relações (ACIOLI, 2007).

Na última parte, após as observações sobre os atores e grupos mais relevantes, este trabalho finaliza com a identificação e análise da rede social do turismo local. Nesse momento o software Ucinet 6.0, alimentado com informações coletadas nas entrevistas, foi essencial. 


\section{O PODER, SUAS FORMAS E ARTICULAÇÕES: FUNDAMENTAÇÃO TEÓRICO- CONCEITUAL}

Os estudos sobre o poder tornam-se diversificados e verticalizados quando se relacionam com o espaço, suas dimensões e demais peculiaridades das sociedades. As relações em um território, segundo Modesto (2008, p. 21) "configuram na realidade, vários conflitos de interesses, especialmente os provenientes das relações sociais, que, por certo, materializam disputas territoriais, as tensões e arranjos." Segundo o autor, essas relações, quando espacializadas, tornam-se um "campo profícuo de análise geográfica" (MODESTO, 2008, p. 21).

Nas relações de poder, mais importante do que agir e de possuir algo, é a capacidade de determinar o comportamento do outro, "uma forma de impor uma vontade à parte mais fraca de uma relação" (CASTRO, 2005, p. 101). O atendimento ou obediência encontrada em uma relação nem sempre é reflexo de uma aceitação. A resistência, ora branda e discreta, ora tumultuada e/ou organizada, é intrínseca a qualquer relação de poder. No entanto, não se pode afirmar que todas as relações devam contar com um perdedor. Na verdade, as relações são, na maioria das vezes, semelhantes a jogos de soma não nula, (...) onde os trunfos são repartidos" (RAFFESTIN, 1993, p. 59).

Os resultados esperados e alcançados nas relações de poder, atuais e passadas, fazem com que uma definição clara e incontestável ainda não tenha sido apresentada pelos pesquisadores. Raffestin (1993, p. 51) considera poder "uma palavra rebelde a qualquer definição". Apesar da dificuldade na elaboração desse conceito, essa é uma tentativa válida, possível por meio de "aproximações sucessivas". É consenso que o poder é "parte intrínseca de toda relação (...), está em todo lugar" (RAFFESTIN, 1993, p. 52).

A influência pode ser ideológica, econômica e/ou política e são consideradas três formas de poder. O poder ideológico é exercido por aquele grupo, indivíduo ou instituição, que usa seu conhecimento para influenciar comportamentos (BOBBIO, 2010, p. 83). A influência econômica imprime uma dinâmica específica nas relações sociais. O poder econômico "se vale da posse de certos bens, necessários ou percebidos como tais, numa situação de escassez, para induzir os que não os possuem a adotar certa conduta, consistente principalmente na execução de um trabalho útil" (SILVA, 2009, p. 4). A terceira forma de poder, o poder político, é considerada por alguns autores como mais importante, por compreender "tanto a possibilidade de coerção, típica do poder despótico, quanto a autoridade, de fundamento legal" (CASTRO, 2005, p. 104). Nas democracias, é essencialmente um poder em relação ao povo e realizado por meio do povo, mas ao contrário do que se espera, raramente é realizado em benefício do povo. Como resultado histórico das relações sociais de poder emergiram os grupos dominantes.

Independente da origem e dos motivos que levaram o homem a se organizar em sociedades, esta é uma característica incontestável do mundo contemporâneo. "Considera-se uma abstração irreal o falar-se em indivíduos ou cidadãos como entes substantes por si mesmos, é dizer, independentemente de um aglomerado que o envolva" (BASTOS, 1986, p. 121). As necessidades individuais vão agrupando pessoas com demandas similares em busca de vantagens comuns, não necessariamente globais. A articulação de interesse consiste no "processo através do qual os indivíduos e os grupos propõem questões às estruturas de decisões políticas" (BOBBIO; MATTEUCCI; PASQUINO, 2000, p. 564-565).

Nesta pesquisa recebem destaque três grupos muito influentes na distribuição do poder: o poder público, entendido aqui na sua íntima relação com o Estado; o capital privado, representado, aqui, pelos detentores de poder econômico e; as entidades representativas que, de forma geral, são compostas por entes públicos e privados. Esses são considerados, nas análises, como grupos de poder do turismo local.

Para Raffestin (1993, p. 16) "dizer que o Estado é a única fonte do poder é, como dissemos, uma confusão.” É necessário reconhecer, que ele é um poder muito estruturado e organizado, mas 
não o único. O entendimento do Estado enquanto único "não é aceitável na medida em que existem múltiplos poderes que se manifestam nas estratégias regionais ou locais" (RAFFESTIN, 1993, p. 17).

A permeabilidade de indivíduos e grupos com o poder público gera efeitos positivos e negativos, sendo uma característica intrínseca ao Estado, no Brasil. "Para uma parte significativa da literatura de ciências sociais, assim como para praticamente todo o senso comum, o Estado brasileiro teria como uma de suas principais características sua interpenetração com atores privados" (MARQUES, 2003, p. 188).

$\mathrm{Na}$ disputa pelo poder de decisão, sempre estiveram presentes com os detentores do poder econômico, grandes industriais e latifundiários principalmente. Prestadores de serviços não se mostraram tão imponentes, ainda que algumas grandes corporações ligadas aos serviços consigam influenciar decisões, isso acontece isoladamente, e não de forma coletiva. Os prestadores de serviços turísticos, principalmente os setores transporte e hotelaria, abriram, com a captação dos grandes eventos, principalmente os esportivos, uma importante via de relacionamento com o poder público em todas suas escalas. No entanto, isso é algo em processo, e ainda não se concretizaram os resultados de suas influências.

As reflexões, até o momento estabelecidas, sobre grupos de poder, voltam-se mais aos nós, ou seja, aos fixos, indivíduos e instituições. Os estudos das redes sociais, apresentados adiante, voltam-se aos fluxos, "envolvem contatos, vínculos e conexões que relacionam os agentes entre si” (MARQUES, 2003, p. 33). Brumes (2010) que a ênfase na análise das redes sociais está nas "relações que se estabelecem entre os indivíduos, instituições e organizações, cujos vínculos estruturam diferentes situações sociais e influenciam o fluxo de bens materiais, ideias, informação e poder" (BRUMES, 2010, p. 81).

Em linhas gerais, o estudo das redes sociais tem por objetivo identificar e descrever os processos sociais que envolvem conexões entre atores, sejam essas conexões entre indivíduos, entre instituições, ou de indivíduos com instituições (FURINI, 2008, p. 180).

As redes sociais são, neste estudo, consideradas uma forma de compreender a realidade por meio das relações de poder, além de um "método para a descrição e a análise dos padrões da relação nela presentes" (MARQUES, 2000, p. 32). A análise das redes sociais não pode ser reduzida à descrição superficial de quem é, ou qual papel desempenha cada nó dessa rede. "O uso de redes nos permite descer a um nível de grande detalhe das relações individuais, sem perder de vista a estrutura do campo inteiro e os padrões gerais observáveis" (MARQUES, 2000, p. 36). Ainda que as considerações acima sejam necessárias a análise exige sua superação.

Os estudos voltados à análise das redes sociais sempre atentam à dinâmica da rede e se debruçam em medições voltadas à estrutura, aos graus de centralidade, de proximidade e intermediação dos atores das redes. Esses dados são capazes de indicar a influência, importância e representatividade de um ator da rede.

São quatro os indicadores que auxiliam nas análises da rede social que serão observados aqui: densidade, centralidade, centralização e intermediação (ALEJANDRO; NORMA, 2005).

Com base nos esclarecimentos teóricos aqui apresentados, o estudo dirige ao município de Campo Mourão - PR, onde se busca compreender as relações de poder, a formação de grupos de interesse, com base na análise da rede social do turismo local.

\section{GRUPOS DE PODER E SETOR DE TURISMO EM CAMPO MOURÃO}

Com 87.194 habitantes é o município polo da mesorregião centro-ocidental do Paraná - COMCAM, que agrega 25 municípios e aproximadamente 334.125 habitantes. O crescimento econômico do município pode ser atribuído ao atual modelo da agricultura que permite produção em larga escala e grandes ganhos, ainda que restritos a poucos produtores locais. Além da agricultura e da crescente agroindústria, novas atividades produtivas dinamizam a economia mourãoense, com 
grandes reflexos no consumo de bens e serviços, tanto que os serviços contribuem com aproximadamente $60 \%$ da composição do PIB municipal. Seu grande representante é o comércio varejista, mas os serviços de saúde, educação, transporte, gastronomia, lazer e entretenimento também têm grandes representantes.

O comércio municipal atende aos moradores do município e de toda a região. Campo Mourão também centraliza grande parte do sistema de saúde dessa região. Destacam-se, também os serviços educacionais, com destaque às instituições de ensino superior. Serviços turísticos também são significativos na cidade, com destaque aos serviços de gastronomia. Dentre estes, os grandes eventos gastronômicos atraem, sazonalmente, grandes fluxos turísticos. De uma forma discreta, porém constante, Campo Mourão conta com fluxo de visitantes cotidiano e significativo. Essas movimentações mais constantes, ocasionadas pelas viagens de trabalho, estudos e negócios são motivadas pelas peculiaridades da atividade produtiva regional e pela centralidade da mesorregião (BRASIL, 2010). Os negócios são responsáveis pela maior dinamização dos equipamentos e serviços turísticos mourãoenses.

Enquanto os tópicos anteriores foram construídos com referências bibliográficas e documentais, aqui a entrevista foi o procedimento mais utilizado, uma vez que as manifestações de poder no turismo em Campo Mourão não são tão evidentes, nem constantemente confirmadas pela mídia. Brumes (2010, p. 85) lembra que cada objeto pode demandar um procedimento específico, "os dados sobre redes sociais podem ser coletados por questionários, entrevistas, diários, observações e, mais recentemente, pelo monitoramento do computador".

O objetivo aqui é identificar os detentores do poder, verificar quais atores emergem como importantes e influentes nas relações de poder em Campo Mourão. A primeira questão solicitava a indicação do nome de três pessoas que mais atuam no desenvolvimento de Campo Mourão. Apenas um dos entrevistados não respondeu essa questão. Alguns dos entrevistados preferiram indicar nome de empresas ou setores, evitando a indicação de uma pessoa. O Presidente de grande cooperativa agroindustrial de Campo Mourão foi o nome mais indicado como importante e influente do desenvolvimento de Campo Mourão, sendo citado por metade dos entrevistados.

$\mathrm{O}$ segundo nome mais indicado foi o do atual prefeito, lembrado por aproximadamente um terço dos entrevistados. Suas indicações, como os destinados à cooperativa, também receberam justificativas diversas. Mas, o fato de que 24 dos 32 entrevistados não citaram o Prefeito indica que o mesmo mantém relações pouco profundas com os agentes do turismo municipal. O prefeito foi indicado por $12 \%$ das entidades representativas, $25 \%$ dos hoteleiros e $50 \%$ dos membros do poder público local, o que, possivelmente, represente suas relações de influência: muito mais intensa entre os membros do poder público, vulnerável entre os hoteleiros, e extremamente frágil dentre as entidades representativas.

Com duas indicações a menos que o prefeito, uma multinacional processadora mundial de carne de frango, bovina e suína com sede em Campo Mourão, foi o terceiro ator mais votado. Além da cadeia produtiva que a processadora imprimiu em Campo Mourão, a empresa também se impõe nas relações sociais, influenciando a opinião pública via imprensa local, o que certamente a colocou entre as mais citadas. "A população é manipulada, voluntariamente ou não, pelo caráter simbólico de crenças, valores e outros, bem como pelos meios de comunicação (que transmitem essas ideologias), legitimando as ações dos grupos detentores do poder" (SILVA, 2008, p. 71).

As Universidades também foram lembradas como influentes. As justificativas estavam relacionadas às ações de apoio, suporte e orientação que as instituições de ensino superior desenvolvem em diversas áreas. Tem-se como verdade, no entanto, que muitas das indicações foram atreladas aos seus responsáveis e aos papéis políticos partidários ou empresariais que representam. Outros 26 atores apareceram nas entrevistas, recebendo cada nome, uma indicação. Nesse grupo foram indicadas empresas locais e/ou seus representantes. Entre essas, três prestadores de serviços turísticos foram lembrados. 
Quanto aos grupos a que estes atores pertencem, é possível traçar algumas considerações. Conforme ilustra o gráfico 1 , os membros do poder econômico receberam quase $60 \%$ das indicações. O poder econômico, representado na Figura 1, é composto por todas as empresas e/ou proprietários indicados e, aparentemente, mostra-se um grupo bastante diversificado, que agrega empresas locais, regionais, nacionais e também internacionais dos diversos setores produtivos.
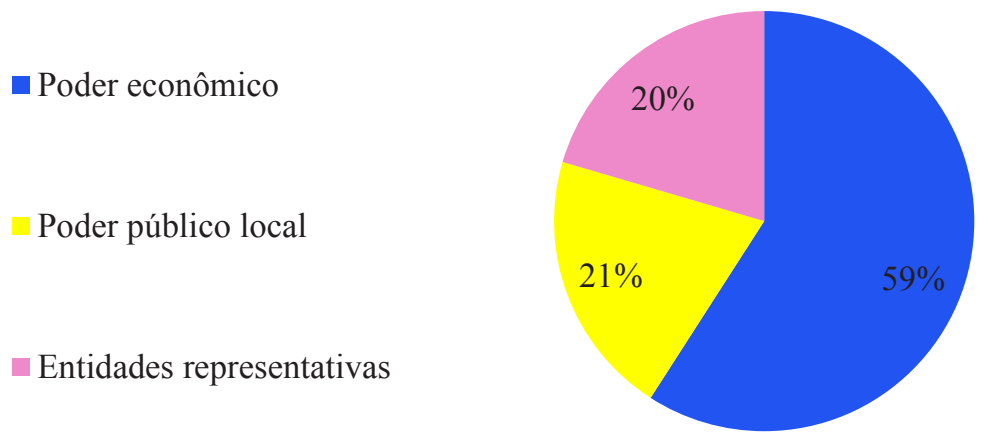

Figura 1 - Gráfico dos Grupos a que pertencem os atores que mais atuam no desenvolvimento de Campo Mourão

Vale lembrar que, ao longo da história do Brasil, o poder econômico e o poder político nunca foram claramente distintos em razão, além de outros, de características como a permeabilidade e a porosidade do Estado. A separação do poder econômico do poder político serve apenas enquanto questão metodológica, pois na realidade pouco se pode distingui-los.

Esta primeira pergunta do roteiro de entrevistas voltava-se a Campo Mourão como um todo, sem nenhuma especificação do setor turístico. No entanto, 30\% dos indicados estão relacionados ao turismo.

Dentre as relações de poder e atores de maior influência identificados, já emergiram alguns membros da hotelaria e do poder público municipal, que são considerados neste trabalho como os atores do turismo local. Busca-se, então, restringir a observação aos atores e grupos do turismo local. Neste ponto, a entrevista solicitava a indicação de três nomes, mas restringindo àqueles que o entrevistado entendesse que seriam as pessoas que mais atuavam na organização do turismo municipal. A análise das respostas nos levou a algumas constatações. Primeiro que, onze dos entrevistados preferiram não responder a esta questão, destes, nove são hoteleiros. Segundo eles, "não tem ninguém" que mereça tal indicação. A princípio, acreditava-se que essa postura de negação da representação da classe aconteceria apenas com os hoteleiros das áreas mais periféricas da cidade, proprietários de empreendimentos de menor porte e que estão há pouco tempo no setor hoteleiro. No entanto, dois hotéis de grande porte, já consolidados no mercado, foram incisivos no fato de que a incipiência do turismo local não permite que sejam indicadas pessoas que realmente atuem na organização do mesmo.

O segundo ponto a destacar foi a dificuldade dos entrevistados em indicar nomes relacionados ao turismo. Neste sentido, os entrevistados salientaram que é possível verificar algumas ações na área do turismo, mas que as mesmas não chegam a representar ações na organização do turismo municipal, pois tais atuações não concretizaram, até o momento, resultados significativos, ilustrando a diferenciação, já mencionada, entre poder potencial e atual de Raffestin (1993).

Segundo os entrevistados, existem ações de qualificação e melhoria em empreendimentos turísticos, mas são ações isoladas, não integradas, e em benefícios próprios, não voltados à organização do setor como um todo, por isso a dificuldade em indicar nomes. Por outro lado, alguns dos entrevistados insistiram na indicação de mais de três nomes, alegando que seria impossível uma hierarquização entre suas indicações, pois todas elas seriam pessoas de relevância semelhante. Ainda assim, foram indicados 29 nomes pelos 23 entrevistados. Tal como na questão anterior, houve um grande número de pessoas que receberam apenas uma indicação. 
Ainda que existam exemplos de membros do poder público envolvidos nas relações do turismo local, acreditava-se, no início desta pesquisa, que grandes empresários da agricultura receberiam várias indicações, em especial nesta questão, pois parece nítido que, em Campo Mourão, a influência desse setor transcende sua área de atuação. Esse destaque confirmou-se nos tópicos anteriores, mas houve declínio da hipótese, pois os atores do turismo local tiveram um reconhecimento maior do que o esperado, a princípio.

Cabe verificar a qual grupo pertencem os nomes indicados. A divisão foi feita com base no principal grupo em que os indicados se inserem, dessa forma, o maior grupo é formado por atores com poder econômico na cidade, com $44 \%$ dos indicados.

No entanto, sabe-se que alguns membros de entidades representativas e do poder público municipal têm também seu reconhecimento devido à influência econômica que exercem. Se membros do poder público e de entidades representativas que têm influência econômica fossem contabilizados, enquanto poder econômico, esse grupo somaria mais de $60 \%$ dos nomes indicados.

Na figura 2, mais uma vez, evidencia a fragilidade do poder público na organização do turismo local. Foi muito mais reconhecida, por parte dos entrevistados, a relevância e a atuação das entidades representativas e do poder econômico, do que dos próprios organismos oficiais de turismo e dos gestores municipais. A incapacidade do poder econômico em organizar o desenvolvimento do turismo local já foi discutida em diversos estudos sobre o setor, que salientam a necessidade da intervenção do poder público para regular a tensa relação entre os interesses privados dos prestadores de serviços turísticos e dos consumidores.
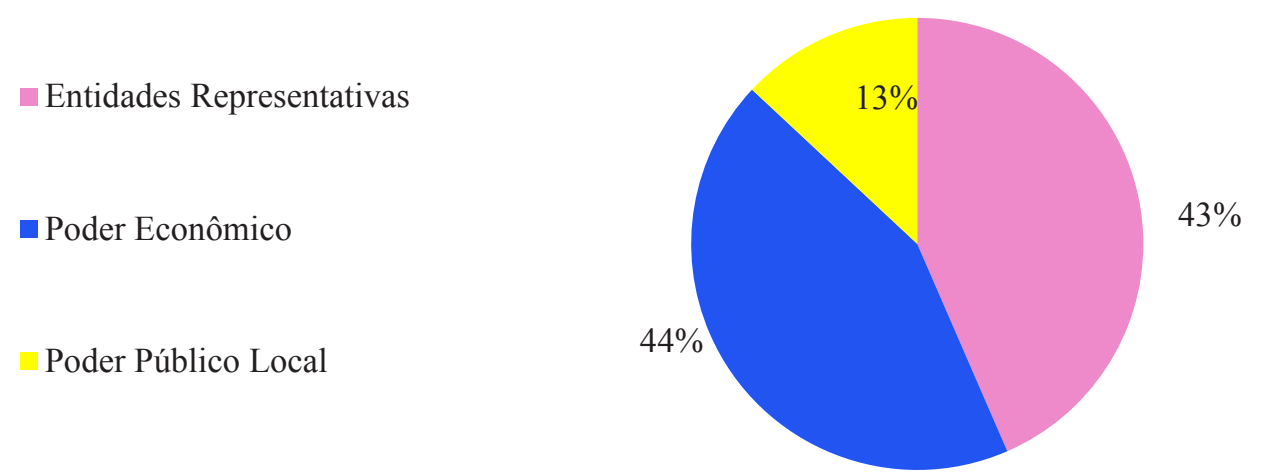

Figura 2 - Gráfico dos Grupos a que pertencem os atores que mais se destacam na organização do turismo local

As indicações dos entrevistados apresentadas até aqui referiam-se ao reconhecimento de atores atuantes, mas, não necessariamente pelos contatos que esses entrevistados estabelecem. A partir daqui, as reflexões voltam-se às relações estabelecidas pelos entrevistados.

Buscou-se verificar os principais órgãos públicos ou entidades não-governamentais que os entrevistados consideravam importantes para a realização de suas atividades. Onze dos entrevistados, $30 \%$ da amostra, preferiram não responder a esta questão. Dez dessas respostas vieram da hotelaria e uma da Governança Regional.

O descontentamento quanto ao apoio dado pelo Município e Estado aos trabalhos relacionados ao turismo ficou nítido nas entrevistas, o que levou a essa grande abstenção, principalmente por parte dos hoteleiros. Ainda assim, dentre os que responderam, a Prefeitura foi a mais indicada e seus aspectos positivos foram, em sua maioria, atrelados a ação do setor de cultura. Dentre os hoteleiros que responderam a pergunta, apenas um não citou as instituições ligadas a Fecomércio. A justificativa dessa escolha deu-se por essas entidades oferecerem cursos, pelas parcerias na qualificação do setor como em diversas ações isoladas, como organização de eventos e até mesmo parcerias mais duradoras. Pelo mesmo motivo as instituições de ensino superior do município receberam significativas indicações. 
Referente a essa pergunta, alguns apontamentos podem ser feitos. De forma geral, verifica-se que os hoteleiros indicaram entidades voltadas à formação e à qualificação de recursos humanos no setor turístico. Alguns órgãos estaduais com escritórios municipais e/ou regionais, em Campo Mourão, foram mais indicados, na somatória geral, do que os setores da prefeitura municipal.

Uma coisa é certa: a energia e a informação sempre estão presentes simultaneamente em toda re $\neg$ lação. A troca verbal, a relação oral, não é puramente informacional, pois é necessário uma quantidade de energia para que a co-municação tenha lugar. O laço entre o poder e o saber é evidente, mas não há nem informação pura nem energia pura. Trata-se sem $\urcorner$ pre de uma combinação das duas. $\mathrm{O}$ espaçotempo relacional é or $\neg$ ganizado pela combinação de energia e informação (RAFFESTIN, 1993, p. 54).

Nenhum hoteleiro indicou membros do poder público municipal entre as pessoas com quem mais se relacionam. Em contrapartida, também não foram indicados por nenhum membro do poder público. Esses, por sua vez, também fizeram várias indicações aos seus pares. Os membros do poder público indicaram cargos administrativos e burocráticos necessários para execução das atividades relativas às suas pastas, além das equipes internas de trabalho.

Nas entidades representativas, as indicações internas foram menos frequentes. Um ponto comum foi a indicação de quatro representantes de associações. Houve, é claro, indicações ao poder político local e agricultores, mas a falta de repetição nessas indicações sugerem que não existe, entre as entidades, parceiros e relações comuns, e que seus vínculos são muito particulares.

A próxima pergunta restringia a resposta a empreendimentos privados. Foram indicadas sessenta e seis empresas. Essa questão foi respondida por todos os entrevistados, com uma espontaneidade muito maior do que quando questionados sobre as pessoas e órgãos do poder público municipal, mas seguindo a regra das questões anteriores, mais de cinquenta dessas empresas receberam apenas uma indicação. Novamente a Cooperativa se destaca, com 14\% de todas as indicações, feitas por membros dos três grupos: poder público municipal, hoteleiros e entidades. Os segundos mais indicados têm quase $10 \%$ menos indicações do que a Cooperativa.

Duas empresas empatam com 5\% de indicação cada. Interessante como podem exercer influência similar com histórias tão diferentes em Campo Mourão. Uma empresa local de transporte rodoviário com 49 anos de história e tradição na cidade exerce a mesma influência que uma multinacional recém chegada. Mais do que resultado de relações sociais, o destaque da multinacional, deve-se ao apoio do poder público municipal que estampa, na mídia, os empregos gerados por ela e vantagens que trará ao município. A exposição da mídia e a parceria declarada com o poder público também facilitam que novas relações sejam estabelecidas, em um tempo tão curto na cidade.

Grande parte das indicações dos hoteleiros foi direcionada às empresas de grande porte ou que apresentam alguma peculiaridade produtiva e, por isso, são capazes de atrair grande número de visitantes e, automaticamente, dinamizar o setor hoteleiro.

\section{REDES SOCIAIS: A REPRESENTAÇÃO DAS RELAÇÕES DE PODER DO TURISMO LOCAL}

As reflexões até agora apresentadas sobre as entrevistas realizadas voltaram-se à verificação, compreensão e análise do poder, ao reconhecimento da influência de atores, grupos e organizações do setor turístico de Campo Mourão. A análise das redes sociais também permite observar esses agentes, no entanto, direciona-se mais especificamente às relações estabelecidas entre eles. Ou seja, as análises de poder permitem maior compreensão dos fixos ou nós e a quantidade de indicações recebidas, enquanto a análise das redes sociais permite maior compreensão das relações, laços ou fluxos, visualizando também quem indicou e qual a capacidade de conectar outros atores.

A análise das relações se torna possível através de um tratamento diferenciado às questões que solicitavam nomes de atores ou organizações com quem os entrevistados mais se relacionavam para a gestão dos equipamentos, serviços e atrativos turísticos sob suas responsabilidades. O menciona- 
do tratamento diferenciado foi facilitado pelo auxílio do software específico para análise de rede social, o Ucinet 6.0. Este programa, após a inserção dos dados, gera um sociograma, ou seja, uma representação "de uma dada rede, onde os nós expressam entidades (pessoas, empresas, associações, etc.) e as linhas representam vínculos entre eles de diversos tipos” (MARQUES, 2003, p. 158).

Cada sociograma é o resultado bem elaborado de uma série de cálculos que possibilita análises quantitativas e qualitativas de uma rede social.

A análise de redes sociais consiste no mapeamento de relações entre seus diversos atores (indivíduos, empresas, instituições, formas de associações) e a representação destes relacionamentos na forma de matrizes e gráficos que possibilitem a realização de análises qualitativas e quantitativas destes relacionamentos (ALMEIDA; D’IPOLITTO, 2007, p. 20).

Além da imagem gerada, o Ucinet dispõe de uma série de ferramentas que permitem a elaboração de cálculos e informações gerais para toda a rede, para cada um de seus nós e informações imprescindíveis na análise das redes, como densidade, centralidade, centralização, intermediação e proximidade. As informações coletadas com os entrevistados permitiram verificar os vínculos existentes e os atores por eles citados. Com esses dados foi possível identificar a rede social formada pelos atores do turismo em local, que diferencia-se principalmente pelo grande número de nós. Os entrevistados relacionam-se com outros 108 nós, resultando, assim, numa rede social de 140 nós vinculados através de 258 laços.

O excessivo número de nós resultou em uma rede social de baixa densidade. A densidade de uma rede é a analogia entre o número de relações existentes em comparação ao número de relações possíveis e, então, uma rede $100 \%$ densa é aquela em que todos os nós estão conectados uns aos outros. A rede social mencionada apresenta um número de relações muito menor do que as possíveis. Com um índice de 1,325\%, pode ser considerada uma rede de densidade extremamente baixa. "Muitos pontos, mas pouco interconectados, caracterizam justamente (...) a fragilidade da rede" (SILVA, 2005, p. 221). Porém, tal índice não avalia se uma rede social é mais ou menos importante, pois ainda que represente uma "estrutura extensa e horizontal não exclui a existência de relações de poder e dependência nas associações internas e nas relações com unidades externas" (MARTELETO, 2001, p. 73). Existem, inclusive, algumas vantagens para as redes sociais mais esparsas ou difusas. As redes dessa natureza "facilitam o acesso às novas informações pelo caráter não redundante das relações; permitem enfrentar a incerteza do ambiente competitivo" (BRANDÃO, 2010, p. 62).

Além da densidade, outro índice importante para a análise das redes sociais é o grau de centralidade de cada ator. Também chamado de grau de entrada, esse índice refere-se à quantidade de "contatos diretos, ou seja, o número de vezes que este foi citado dentro do total possível" (NASCIMENTO, 2010, p. 155).

Neste estudo, o número de indicações possíveis refere-se ao número de entrevistados. Os elos mais citados são considerados "vínculos fortes estão mais associados a controle e hierarquia" (MARQUES, 2003, p. 165-166). A centralidade observada na rede social coloca em destaque um hotel tradicional no município, citado por $50 \%$ dos entrevistados. Apesar do nítido destaque deste ator, este ainda não estabelece relação com a maioria dos nós.

Calcular a centralidade de um ator significa identificar a posição em que ele se encontra em relação às trocas e à comunicação na rede. Embora não se trate de uma posição fixa, hierarquicamente determinada, a centralidade em uma rede, traz consigo a idéia de poder. Quanto mais central é um indivíduo, mais bem posicionado ele está em relação às trocas de comunicação, o que aumenta seu poder na rede (MARTELETO, 2011, p. 76).

O segundo maior índice de centralidade é representado por dois atores, a Prefeitura e a já mencionada Cooperativa Agroindustrial, ambos foram indicados por aproximadamente um terço dos 
entrevistados. Como hipótese confirmada, a Cooperativa desempenha papel central nas relações em Campo Mourão, seja na agricultura, indústria, serviços e até mesmo no setor de viagens e turismo. Esse reconhecimento é de 'senso comum' no município e são raros os estudos sobre Campo Mourão que ignorem a importância de tal cooperativa, fato que também se confirma aqui. Ainda que não tenha sido citada como uma relação frequente por todos os atores, o nome dessa cooperativa foi sempre citado. Apenas oito entrevistados não a citaram entre suas relações ou não a indicaram como importante para o desenvolvimento local e regional. Mostrando que nas redes sociais encontra-se consenso e alianças, mas raramente unanimidade, pois a característica mais marcante da rede é o conflito, o "movimento dialético de oposições, confrontos e alianças" (BRUMES, 2010, p. 76).

O segundo hotel indicado ocupa a quinta posição no grau de centralidade. Não convém aqui a reflexão completa sobre a centralidade, mas entende-se interessante salientar que o topo da mesma tem representantes diferenciados. Representando o poder econômico está uma grande corporação como a Cooperativa, mas também uma empresa local como o hotel. Enquanto órgão público, a prefeitura municipal se destaca, mas a posição da universidade, órgão público estadual, também é significativa. Dos sete nós com maior grau de centralidade, apenas dois são essencialmente turísticos, os hotéis. Esse resultado reforça que o poder público e os grandes detentores de poder econômico, continuam como atores hegemônicos, sendo capazes de exercer influência mesmo em relações que não estão entre suas principais áreas de interesse, como o turismo.

Vale lembrar que a centralidade é construída a partir das indicações recebidas e, por isso, muitos atores que foram selecionados para entrevista pelo evidente papel no setor turístico municipal, não foram indicados nem mesmo por seus pares, sugerindo que, apesar do papel teoricamente atribuído, suas ações não se desdobram em relações e influências. Chama mais atenção o fato de nove dos nós considerados atores do turismo local, um terço do total, não foram citados. Esses nós participam das redes apenas pelas relações que afirmam estabelecer, mas não pelo reconhecimento dos outros nós. Ou seja, a Cooperativa, diversas vezes mencionada, se mostra mais nas relações de poder deste setor do que 15 hotéis, que todas as entidades representativas e órgãos públicos voltados à gestão do turismo.

Outro índice que deve ser considerado na análise das redes sociais é a centralização. "A centralização, ao contrário da centralidade, mensura o total das conexões para cada ator, mas o faz no conjunto da rede" (SILVA, 2005, p. 221). Para se calcular o índice de centralização considera-se os fluxos em todas as direções, ou seja, além das indicações que um ator recebeu (centralidade), também deve-se incluir as relações que ele afirma estabelecer com outros atores, as suas relações indiretas.

Ainda sem essa confirmação pelo outro nó (que em grande parte das vezes existe), as relações indiretas são indispensáveis à compreensão das redes sociais, pois a "informação circula na rede, atingindo os atores também de forma indireta. Isso significa que não só a quantidade de elos diretos define a posição dos integrantes de uma rede" (MARTELETO, 2001, p. 73). Silva (2005, p. 220) complementa, afirmando que "a quantidade de elos indiretos que permitem compreender, assim, seu grau de centralização".

Dessa forma, o resultado da centralidade muda ao se comparar com os dados sobre a centralização, mas a alteração dos resultados ocorre apenas com os nós abordados nas entrevistas, o que já altera a hierarquia na centralização do poder.

Quanto aos graus de centralização, observa-se que o Hotel, com maior grau de centralização, mantém a primeira posição, já atingida na centralidade. No entanto, em razão das alterações no grau de centralização de saída, as próximas posições se alteram significativamente, trazendo muitos atores com pequena centralidade, entre os maiores graus de centralização.

Exemplo disso é o Hotel B que ocupa o segundo maior grau de centralização. Isso acontece porque grande parte do poder que o hotel desempenha na rede social do turismo local vem das relações que ele estabelece com atores que não foram entrevistados e por não estar entre as relações mais frequentes dos entrevistados. 
Em menores proporções, essa diferença entre o grau de centralização de entrada e de saída, e o maior resultado total, devido ao grau de saída, acontece com órgãos estaduais e hotéis. Outros atores do turismo local também atingem maior grau de centralização graças ao grau de saída. Os demais nós não avançam aqui (em relação a centralidade) em função unicamente de suas respostas, sendo que assim a diferença entre os graus de centralização de entrada e de saída não é tão extrema.

Por outro lado, alguns entrevistados indicaram poucos nomes, confirmando seu isolamento na gestão do turismo e o pequeno número de relações que estabelecem. Este é o caso, por exemplo, de dois hotéis que, além de não serem citados por nenhum ator, citaram apenas dois nós com os quais se relacionam, apesar da insistência para que fossem apresentados ao menos nove nomes. Todas essas relações, reflexo da centralização, podem ser observadas no sociograma 1 onde os nós que representam os atores do turismo local, abordados nas entrevistas, foram diferenciados pela cor.

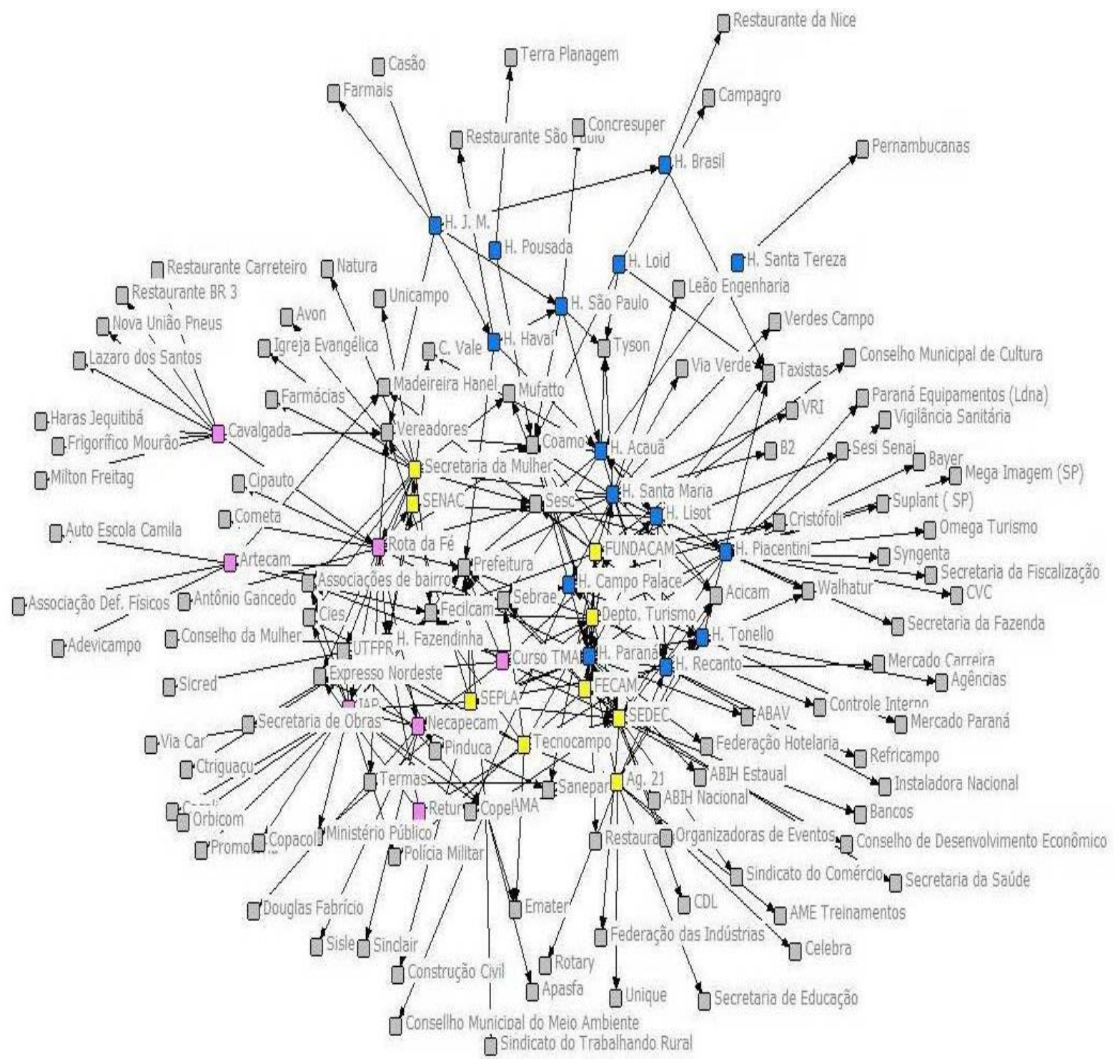

Figura 3 - Sociograma 1 - Rede social do turismo local Fonte: Entrevistas (2011) e Ucinet 6.0.

De posse do grau de centralização de entrada e de saída de cada ator da rede social, o programa Ucinet 6.0 calcula índices de centralização de entrada e de saída para a rede como um todo. Esse índice varia de 0 a 100\%. Uma rede social com grau de centralização de $100 \%$ é aquela em que existe um ator central, altamente conectado à rede, sendo o único que estabelece relações com todos 
os outros nós. A centralização máxima "é uma condição especial em que um ator exerce um papel claramente central ao estar ligado a todos os nós, os quais necessitam de passar pelo nó central para se ligarem uns aos outros" (ALEJANDRO; NORMAN, 2005, p. 20). No processo inverso, quando as relações são distribuídas de maneira proporcional entre todos os nós, sem um ator de destaque, o grau de centralização é $0 \%$. Os "valores baixos neste indicador indicariam a ausência de actores claramente centrais" (ALEJANDRO; NORMAN, 2005, p. 20). Este é o caso da rede social em questão, que tem como grau de centralização de entrada 10,258\%, e grau de centralização de saída de $11,707 \%$.

Outro indicador indispensável na análise das redes sociais é o Grau de Intermediação de cada ator. A capacidade de intermediação de um ator expressa sua capacidade de controlar a comunicação na rede, sua capacidade de servir como ponte entre outros nós. Por meio de tal indicador "interpreta-se qual a possibilidade que um nó tem para intermediar as comunicações entre pares de nós" (ALEJANDRO; NORMAN, 2005, p. 20).

Novamente com o auxílio de cálculos e relatórios gerados pelo programa Ucinet 6.0 foi possível verificar a capacidade de intermediação de cada nó da rede. Assim, os dados sobre intermediação indicam que um Hotel, ainda não mencionado nas análises aqui apresentadas, tem maior capacidade de intermediação. Ele está em posição favorável, ao fazer conexões entre pares de atores na rede.

As reflexões sobre os papéis e responsabilidades dos atores no turismo atribuem ao poder público e as associações o papel de articular nós e intermediar interesses, visto que entre seus compromissos estão os interesses de seus representados. Porém aqui, destacam-se os hoteleiros, com os cinco maiores graus de intermediação. Os representantes do poder público municipal e os órgãos gestores do turismo, que deveriam estimular a articulação no setor, aparecem em $13^{\circ} \mathrm{e}$ $17^{\circ}$ lugares. Muitos dos nós apresentam grau de intermediação zero, ou seja, não se encontram no caminho da relação entre outros nós, não intermediam relações entre dois nós. Essa incapacidade de intermediação é comum a atores supostamente relevantes na rede social do turismo local, como hotéis, associações, e entidades representativas.

É interessante sintetizar alguns índices já apresentados, restringindo as análises aos atores indicados como centrais e aos índices alcançados pelo Departamento de Turismo da Secretaria de Desenvolvimento Econômico da prefeitura de Campo Mourão.

Ainda com a pequena participação de alguns hotéis na rede estudada, os índices apresentam uma alternância nas posições de destaque das relações de poder, mas o revezamento ocorre apenas entre o capital privado (os hoteleiros). É possível observar que o capital privado, aqui representado pelos hotéis, desempenha papel mais significativo na rede social do turismo local do que o poder público em todos os indicadores avaliados. No entanto, parece que isso ocorre mais por um descaso do poder público com o papel que deve desempenhar do que pela disputa dos detentores do poder econômico por esses papéis centrais. Tal desempenho na rede é ilustrado na figura 4.

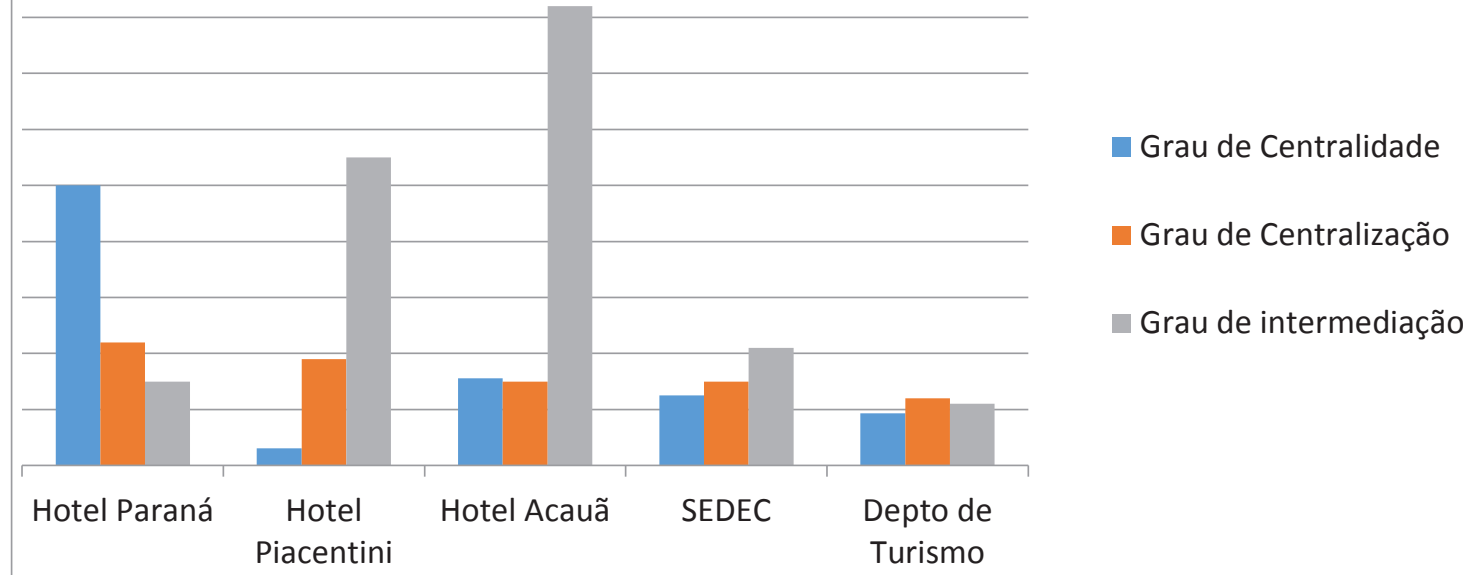

Figura 4 - Gráfico de Comparação entre os indicadores da rede social do turismo local 
Apesar do número de pessoas e instituições, pode-se perceber que muitos deles são atores periféricos, com frágeis relações, ou seja, se inserem na rede por apenas uma relação e, sendo as redes representações muito momentâneas, esses vínculos podem facilmente se romper e esses atores deixarem de fazer parte da rede de relações do turismo. "Seriam fracos os elos citados apenas uma vez em qualquer das entrevistas realizadas (...). Os vínculos fracos são muito importantes para veicular informação e produzir coordenação e ação conjunta" (MARQUES, 2003, p. 165).

A importância dos vínculos fracos é confirmada por Brumes (2010). Para a autora, as redes sociais podem ser comparadas a um sistema de tensões, onde cada elo, individualmente tem uma função para os nós que liga, como tem também grande relevância na totalidade da rede, independente de ser, um de seus nós, considerado forte ou fraco.

Sistema de tensões para o qual cada fio isolado concorre, cada um de maneira um pouco diferente, conforme seu lugar e função na totalidade da rede. No entanto, essa rede nada é além de uma ligação de fios individuais; e, no interior do todo, cada fio continua a constituir uma unidade em si; tem uma posição e uma forma singular dentro dele (BRUMES, 2010, p. 72).

O turismo, ao envolver diversos setores da economia, gera uma rede com muitos nós, muitos deles, frágeis. Porém, é uma rede singular que permite reflexões profundas e indica os caminhos pelos quais o poder e a influência circulam na rede.

\section{CONSIDERAÇÕES FINAIS}

O Turismo, enquanto fenômeno social, envolve diversos setores produtivos e reflete em amplos aspectos da sociedade com ligação direta e indireta com a atividade. Compreender o turismo em sua complexidade exige também compreender locais excluídos dessa lógica, ou seja, parece um tema sem fim.

Mais complicado ainda é dar conta das considerações sobre a Geografia, o Turismo e o poder, principalmente o poder local que envolve uma gama de relações pessoais, familiares, de amizade, profissionais, dentre outras. O poder local não pode ser tratado única e reduzidamente pelo viés econômico ou pelo viés político. O estudo do poder, espacialmente delimitado em uma sociedade, deve dar conta de analisar as mais diversas formas de relações ou influências que ali se estabelecem ou que influenciam a realidade observada. Ambos, o poder e o turismo, são fundamentados nas relações. Se não há poder sem relação, também não emerge um exemplo de turismo que não se estabeleça nas relações sociais, nas relações de poder.

As primeiras considerações versam sobre as formas de poder e articulação de interesse no turismo local. As diferenciadas formas de poder demonstram que, também no turismo, o poder econômico torna-se uma referência. Pequenos investidores dos serviços turísticos almejam, além do acúmulo de capital, o poder de decisão e a influência demonstrados pelos grandes atores econômicos hegemônicos, acreditando que ao alcançar grandes ganhos econômicos também acumularão maiores contatos, carisma e influência sobre as decisões.

Em Campo Mourão, os pequenos e médios investidores da hotelaria demonstram a compreensão de que apenas o acúmulo do poder econômico é capaz de trazer o carisma e a influência, esquecendo que o poder político pode ser facilitado pelo poder econômico, mas não é a única maneira de acesso ao poder político, ao poder de decisão, à influência. A capacidade de estabelecer relações pode substituir o poder econômico, mas isso não convence a pequena hotelaria mourãoense, pois esta mostra-se convencida de que, em razão do pequeno fluxo de negócios que realizam, não é capaz de se impor, de influenciar decisões favoráveis ao setor e, por isso, deixam esse papel aos proprietários dos maiores hotéis da cidade.

Mais preocupante ainda é saber que o setor não está fortemente articulado. Esse papel de representante da hotelaria atribuído aos maiores hotéis não advém do diálogo e do acordo, nem do 
reconhecimento da capacidade dos grandes, mas da incapacidade dos pequenos e médios hoteleiros. Ainda que muitas das demandas e interesses tenham se assemelhado ou demonstrado serem comuns, não há garantias nem cobranças de quais interesses venham a ser defendidos ou tratados como prioritários. Neste caso, não é possível fugir da influência do poder econômico ao analisar uma atividade essencialmente econômica.

As relações sobre o turismo local não estão constantemente na mídia, que sempre comunica apenas os interesses e reflexos da influência da agricultura e da indústria, temas maior destaque de forma geral. Assim, nem todas as relações de poder emergem aos olhos da sociedade, sendo este o caso das relações de poder via turismo. Para buscar compreender como se dão estas relações recorreu-se a análise das redes sociais.

A rede social do turismo local estudada é extensa e seus nós representam organismos diversos: a) as entidades representativas; b) o poder público municipal e; c) o capital privado. As entidades são diversificadas e estão representadas na rede social do turismo por associações empresariais, de bairros, de afinidades, entre outras. Em relação ao poder público municipal, são nós da rede social do turismo atores ligados ao transporte, cultura, meio ambiente, obras, fiscalização, entre outros. Ainda ligados ao poder público, a rede social do turismo estudada conta com a participação de atores públicos de outras escalas. O capital privado está representado por grande número de empresas de diferentes portes e setores, tendo representantes da agropecuária, indústria e diversos prestadores de serviços, localizados não só em Campo Mourão, mas em outras localidades.

Apesar do grande número e origem de atores da rede social do turismo local, a participação é caracterizada pela desigualdade. As entidades representativas são importantes na captação de fluxos de visitantes para Campo Mourão, mas não desempenham papel de destaque nas relações, ou seja, nos indicadores das redes sociais.

$\mathrm{Na}$ rede social do turismo, formada pelos grupos de poder, os papéis mais significativos, de acordo com os indicativos analisados, são desempenhados pelos hoteleiros. Mas, a rede indica que os grupos de poder do turismo local estabelecem significativas relações internas, mas também se relacionam entre si. Há permeabilidade entre os grupos, mais precisamente das entidades representativas e dos hotéis nas decisões do poder público municipal.

A rede social do turismo local opera com alguns fluxos de cooperação e associação, mas na maioria das relações a divergência e o conflito são mais evidentes. Ao colocar em evidência relações de poder e influência que permeiam as decisões do turismo, o estudo das redes sociais mostra-se uma forma de compreender a sociedade. Sua análise configura-se numa ferramenta do planejamento turístico local e regional, ao possibilitar a compreensão das dinâmicas dos relacionamentos, dos domínios e caminhos das informações e do "conhecimento que nutrem o capital social, revelar os papéis e padrões de relacionamentos dos atores (...) responsáveis pela mobilização, pelo dinamismo, pela busca da inovação voltada para a melhoria das condições de vida da população" (BRANDÃO, 2010, p. 64).

As posições relevantes não estavam evidentes apenas com a tabulação das entrevistas e elaboração dos gráficos. A análise da rede social do turismo local foi determinante para revelar o papel singular de alguns atores em articular e mobilizar todos os demais atores da rede.

Torna-se, então, importante instrumento de gestão, pois indica quem são os atores com influência reconhecida, os nós com maior proximidade, capacidade de atingir outros nós, circular informações ou intermediar relações. A análise da rede destaca os caminhos que devem ser seguidos, e os atores capazes de mobilizar a interação e a articulação do poder local. Os caminhos existem e foram evidenciados no sociograma apresentado. Falta diálogo e cooperação entre os nós para que circulem, na rede, informações em busca de reconhecer interesses comuns, pois apenas esses são capazes de articular o poder local para exercer influência nos tomadores de decisão em busca de benefícios comuns. 
Apesar de não usar com frequência suas relações para articular benefícios, não é possível considerar a rede social do turismo local uma rede fraca, pois apesar de sua baixa densidade, ficou evidenciado que existem atores fortes com várias relações e capacidade de influenciar decisões de outros atores, inclusive em outras escalas. Na rede social do turismo local de Campo Mourão, emergem alguns atores políticos relevantes, capazes de influenciar decisões no cenário estadual e nacional, como grandes empresários dos serviços, da agricultura e da indústria, deputados, diretores de instituições de ensino, secretários municipais, vereadores, dentre outros. O cenário observado em relação ao turismo nesta cidade exemplifica a realidade de diversos municípios do país que não estão em destaque no cenário turístico estadual e nacional.

Em Campo Mourão, a hotelaria se mostra como o mais forte ator político do turismo municipal, mas nenhum grupo isoladamente é mais capaz de influenciar decisões do que aquele formado por uma diversidade de representantes.

\section{REFERÊNCIA BIBLIOGRÁFICA}

ACIOLI, Sonia. Redes sociais e teoria social: revendo os fundamentos do conceito. Informação \& Informação, Londrina, v. 12, p. 01-12. 2007.

ALEJANDRO, Velázquez Álvarez O.; NORMAN, Aguilar Gallegos. Manual introdutório à análise de redes sociais. México, jun. 2005.

ALMEIDA, Maria Beatriz da S.; D’IPOLITTO, Cláudio. A análise de redes sociais como ferramenta estratégica de desenvolvimento regional: O caso do Município de Silva Jardim, no Rio de Janeiro. Inteligência Empresarial, Rio de Janeiro, n. 30, p. 19-27, abr. 2007.

BASTOS, Celso Ribeiro. Curso de teoria do Estado e ciência política. São Paulo: Saraiva, 1986.

BOBBIO, Norberto. Estado, Governo, Sociedade: para uma teoria geral da política, Rio de Janeiro: Paz e Terra, 2010.

BOBBIO, Norberto; MATTEUCCI, Nicola; PASQUINO, Gianfranco. Dicionário de política. v. 2. São Paulo: Imprensa Oficial, 2000.

BRANDÃO, Pâmela de Medeiros. Análise da Rede Política do Turismo Brasileiro. Natal: UFRN, 2010. 215 f. Dissertação (mestrado em Turismo) Pós-Graduação Turismo, Centro de Ciências Sociais Aplicadas da Universidade Federal do Rio Grande do Norte, Natal, 2010.

BRASIL. Instituto Brasileiro de Geografia e Estatística (IBGE): IBGE Cidades. Disponível em: <www. ibge.gov.br>. Acesso em 16 de jul. 2010.

BRASIL. Ministério do Turismo: Dados e Fatos. Disponível em: < http://www.dadosefatos.turismo.gov. br >. Acesso em 23 de abr. 2012.

BRUMES, Karla Rosário. Redes em espaços migratórios: Uberlândia - MG. Presidente Prudente: UNESP, 2010. 280 f. Tese (doutorado em Geografia) Programa de Pós-Graduação em Geografia, Faculdade de Ciências e Tecnologia, Universidade Estadual Paulista, Presidente Prudente, 2010.

CASTRO, Iná Elias de. Geografia e Política: Território, escalas de ação e instituições. Rio de Janeiro: Bertrand Brasil, 2005.

FURINI, Luciano Antonio. Redes Sociais Temáticas: O caso das redes sociais de assistência à criança e ao adolescente em Presidente Prudente (SP) e suas representações sociais. Presidente Prudente: UNESP, 2008. 255 f. Tese (doutorado em Geografia) Programa de Pós-Graduação em Geografia, Faculdade de Ciências e Tecnologia, Universidade Estadual Paulista, Presidente Prudente, 2008.

MARQUES, Eduardo Cesar. Redes sociais, instituições e atores políticos, na cidade de São Paulo, Annablume, São Paulo-SP, 2003.

MARTELETO, Regina Maria. Análise de redes sociais - aplicação nos estudos de transferência da informação. Ciência da Informação, Brasília, v. 30, n.1, p. 71-81, jan./abr. 2001.

MODESTO, Nilo Sérgio d'Avila. A (re)produção espacial em marcha na consolidação dos Grupos de Poder Hegemônico em São Gonçalo - RJ: UFF, 2008. 203 f. Tese (doutorado em Geografia) Programa de Pós-Graduação em Geografia, Universidade Federal Fluminense, Rio de Janeiro, 2008. 
NASCIMENTO, Wagner Cipriano do. As relações de poder no contexto político-econômico de Foz do Iguaçu-PR: UEM, 2010. 232 f. Dissertação (mestrado em Geografia) Programa de Pós-Graduação em Geografia, Universidade Estadual de Maringá. Maringá, 2010.

RAFFESTIN, Claude. Por uma geografia do poder. Tradução Maria Cecília França. São Paulo: Ática, 1993. SILVA, Márcia da. Territórios conservadores de poder no centro-sul do Paraná: UNESP, 2005. Tese (doutorado em Geografia). Faculdade de Ciências e Tecnologia da Universidade Estadual Paulista. Presidente Prudente, 2005.

SILVA, Márcia da. Poder Local: Conceito e exemplos de estudos no Brasil. Sociedade \& Natureza, Uberlândia, v. 20, n. 2, p. 69-78, dez. 2008.

SILVA, Márcia da. Estado e poder local: ensaio teórico sobre estudos no Brasil. Biblio 3W. Revista bibliográfica de geografía y ciencias sociales. Barcelona: Universidad de Barcelona. Vol. XIV, nº 841, 30 de septiembre de 2009. Disponível em: <http://www.ub.es/geocrit/b3w-841.htm> Acesso em 21 de nov. 2009.

Trabalho enviado em novembro de 2012

Trabalho aceito em janeiro de 2013 